Pacific Journal of Mathematics

POLYNOMIALS IN LINEAR RELATIONS

mICHAEL JOSEPH KASCIC, JR. 


\title{
POLYNOMIALS IN LINEAR RELATIONS
}

\author{
M. J. KASCIC, JR.
}

We point out an error in a paper on linear relations by R. Arens. We also re-establish, in a weakened form, a result of Arens on the polynomials in a closed linear relation which was placed in jeopardy by this error.

The error in question is in the proposition [1,3.52], restated below as 3.1. It was detected by Professor P. R. Masani, who also constructed a counter example. We take the liberty of presenting his example below.

The theorem on closed linear relations, viz. [1, 3.8], which depended on this proposition 3.1 was to be a generalization of the theorem of A. E. Taylor $[7,6.1]$ who proved that if $T$ is a closed operator with a nonempty resolvent in a Banach space, then each polynomial in $T$ is also a closed operator.

Our weakened form, viz. Theorem 3.16 below, of Arens' purely algebraic proposition involves topological linear space concepts, and is still a generalization of Taylor's theorem $[7,6.1]$.

2. Linear relations. Let $X_{1}, X_{2}$, and $X_{3}$ be linear spaces. A relation between $X_{1}$ and $X_{2}$ is a subset of $X_{1} \oplus X_{2}$. A linear relation between $X_{1}$ and $X_{2}$ is a linear subspace of $X_{1} \oplus X_{2}$ These concepts generalize the notions of function and linear operator respectively. If $T$ is a relation, the definitions of the domain and range of $T, D(T)$ and $R(T)$ respectively, are obvious.

If $S$ and $T$ are relations between $X_{1}$ and $X_{2}$,

$$
S+T=\left\{\left(x_{1}, x_{2}+x_{3}\right):\left(x_{1}, x_{2}\right) \in S \text { and }\left(x_{1}, x_{3}\right) \in T\right\}
$$

is a relation between $X_{1}$ and $X_{2}$. If $S$ is a relation between $X_{1}$ and $X_{2}$, and $T$ is a relation between $X_{2}$ and $X_{3}, T \circ S=\left\{\left(x_{1}, x_{3}\right):\left(x_{1}, x_{2}\right) \in S\right.$ and $\left(x_{2}, x_{3}\right) \in T$ for some $\left.x_{2} \in X_{2}\right\}$ is a relation between $X_{1}$ and $X_{3}$. For any relation $T, T^{-1}=\{(p, q):(q, p) \in T\}$. If $T$ is linear, $T^{-1}$ is also. If $S$ and $T$ are linear, $S+T$ and $S \circ T$ are also. If $\lambda$ is an element of the field, we may consider $\lambda$ as the linear relation between $X_{i}$ and $X_{i}$, namely $\left\{(x, \lambda x): x \in X_{i}\right\}$. We write $\lambda T$ for $\lambda \circ T$.

If $X_{i}$ and $Y_{i}, i=1,2$, form a dual pair, i. e., there exists a canonical bilinear form $\langle\rangle:, X_{i} \oplus Y_{i} \rightarrow F$ (where $F$ is the field) such that $\left\langle x, y_{0}\right\rangle=0$ for every $x \in X_{i}$ implies $y_{0}=0$ and $\left\langle x_{0}, y\right\rangle=0$ for every $y \in Y_{i}$ implies $x_{0}=0$, and $T$ is a relation between $X_{1}$ and $X_{2}$, we may define the adjoint of $T, T^{*}=\left\{\left(y_{2}, y_{1}\right)\right.$ : for every 


$$
\left.\left(x_{1}, x_{2}\right) \in T,\left\langle x_{1} y_{1}\right\rangle=\left\langle x_{2}, y_{2}\right\rangle\right\}
$$

which is a relation between $Y_{2}$ and $Y_{1}$. Again if $T$ is linear, $T^{*}$ is also. We can also consider $X_{1} \oplus X_{2}$ and $Y_{1} \oplus Y_{2}$ to form a dual pair with $\left\langle\left(x_{1}, x_{2}\right),\left(y_{1} y_{2}\right)\right\rangle=\left\langle x_{1}, y_{1}\right\rangle+\left\langle x_{2}, y_{2}\right\rangle$. Thus we may speak of $T^{\perp}$ for $T$ a relation. From $[1,3.3]$ it is obvious that $T^{* *}=T^{\perp \perp} . \mathrm{A}$ relation is called regularly closed if and only if $T=T^{\perp \perp}=T^{* *}$.

If $X$ and $Y$ form a dual pair over C, we consider $X$ as a class of linear functionals on $Y$. An obvious topology of importance on $X$ is that of pointwise convergence on $Y$. This topology is denoted $\sigma(X, Y)$. It can be shown that the dual of $(X, \sigma(X, Y))$ is $Y$. The interested reader is referred to Schaefer [6], page 122 et seq. A locally convex vector topology on $X, \Omega$, such that the dual of $(X, \Omega)$ is $Y$ is called a consistent topology for the dual pair $\langle X, Y\rangle$. It was shown by Mackey [5] that there exists a finest such topology. Arens [2] identified it with the topology of uniform convergence on absolutely convex $\sigma(Y, X)$ compact sets. This topology is denoted $\tau(X, Y)$. Thus a locally convex vector topology on $X$ is consistent if and only if it is coarser than $\tau(X, Y)$ and finer than $\sigma(X, Y)$.

It was first shown by Banach [3] that if $T$ is a linear subspace, and thus in particular, a linear relation, it is regularly closed if and only if it is closed in the Cartesian product of any two consistent topologies. Thus the question of closed linear relations can be attacked from either viewpoint. Granted that the algebraic approach does not depend on the field, we will see that the topological approach can lead to stronger results in special cases.

3. Closed products of linear relations. In the course of investigating when the product $S \circ T$ of two closed linear relations is closed, Arens [1,3.52] states the following proposition.

Proposition 3.1. Let $X_{i}$ and $Y_{i}, i=1,2,3$ be dual pairs. Let $T$ be a linear relation between $X_{1}$ and $X_{2}$ and $S$ a linear relation between $X_{2}$ and $X_{3}$. If $D\left(S^{*}\right)=X_{3}$ or $R\left(T^{*}\right)=X_{1}$, then $(S \circ T)^{*}=$ $T^{*} \circ S^{*}$. The following counterexample is due to Masani:

3.11. Let $X_{i}=Y_{i}=$ Hilbert space $i=1,2,3$, with its own natural duality. Let $M$ be a closed subspace of $X$ such that the dimension of $M=\infty$. Let $P_{M}$ be the projection onto $M$ and $T_{1}=$ $P_{M}^{-1} \circ P_{M}$. Let $S_{1}$ be any closed one-to-one operator such that $D\left(S_{1}\right) \perp M$ and $R\left(S_{1}\right)$ is not closed. $S_{1}$ may even be chosen to be continuous. We shall first establish that $S_{1} \circ T_{1}$ is not closed. Let $z \in \overline{R\left(S_{1}\right)}-R\left(S_{1}\right)$ and $z_{n}$ a sequence such that $z_{n} \rightarrow z$ and $z_{n} \in R\left(S_{1}\right)$. Let $y_{n}=S_{1}^{-1}\left(z_{n}\right)$. Certainly the sequence $y_{n}$ does not converge (since $z \notin R\left(S_{1}\right)$ ). However, 
$y_{n} \in D\left(S_{1}\right) \subseteq N\left(T_{1}\right)$. Since $T_{1}=T_{1}^{-1},\left(0, y_{n}\right) \in T_{1}$. Since $\left(y_{n}, z_{n}\right) \in S_{1}$, we have $\left(0, z_{n}\right) \in S_{1} \circ T_{1}$. Now since $z \notin R\left(S_{1}\right) \leqq R\left(S_{1} \circ T_{1}\right), z \notin R\left(S_{1} \circ T_{1}\right)$. Thus $(0, z) \notin S_{1} \circ T_{1}$. However $\left(0, z_{n}\right) \rightarrow(0, z)$ and $\left(0, z_{n}\right) \in S_{1} \circ T_{1}$. Thus $S_{1} \circ T_{1}$ is not closed.

Now let $S=T_{1}^{*}$ and $T=S_{1}^{*}$. Then $D\left(T_{1}\right)=D\left(S^{*}\right)=X$. But $T^{*} \circ S^{*}=S_{1}^{* *} \circ T_{1}^{* *}=S_{1} \circ T_{1}$ which we have shown to be not closed. But $(S \circ T)^{*}$ is necessarily closed since all adjoints are; hence $(S \circ T)^{*} \neq T^{*} \circ S^{*}$.

The reader should note that the above counter example also disproves Arens [1, 3.7] on the closedness of $S \circ T$.

As Masani has suggested, there is a weakened form of 3.1 which is true and we present it next (3.12). We remark that 3.12 cannot be used in place of 3.1 in [1] to validate the proposed generalization $[7,6.1]$.

Proposition 3.12. If $T \subseteq X_{1} \oplus X_{2}, S \subseteq X_{2} \oplus X_{3}$ and either $R\left(T^{*}\right)=Y_{1}$ and $D(S) \subseteq R(T)$ or $D\left(S^{*}\right)=Y_{3}$ and $R(T) \subseteq D(S)$, then $(S \circ T)^{*}=T^{*} \circ S^{*}$.

Proof. First note that if one hypothesis is sufficient for the intended result, the other is also. This is an easy consequence of the fact that $(S \circ T)^{*}=T^{*} \circ S^{*}$ if and only if

$$
\left(T^{-1} \circ S^{-1}\right)^{*}=\left(S^{-1}\right)^{*} \circ\left(T^{-1}\right)^{*} .
$$

Thus let us suppose $R\left(T^{*}\right)=Y_{1}$ and $D(S) \subseteq R(T)$. It is trivial that $T^{*} \circ S^{*} \subseteq(S \circ T)^{*}$. Thus we are reduced to showing that

$$
(S \circ T)^{*} \subseteq T^{*} \circ S^{*}
$$

Let $\left(y_{3}, y_{1}\right) \in(S \circ T)^{*}$. Certainly $\left(y_{2}, y_{1}\right) \in T^{*}$ for some $y_{2} \in Y_{2}$ since $R\left(T^{*}\right)=Y_{1}$. If we can show $\left(y_{3}, y_{2}\right) \in S^{*}$, we are finished. To do this we must show for every $\left(x_{2}, x_{3}\right) \in S,\left\langle x_{2}, y_{2}\right\rangle=\left\langle x_{3}, y_{3}\right\rangle$. Since $D(S) \subseteq R(T)$, for each $\left(x_{2}, x_{3}\right) \in S$, there exists $x_{1} \in X$, such that $\left(x_{1}, x_{2}\right) \in T$. Thus $\left\langle x_{1}, y_{1}\right\rangle=\left\langle x_{2}, y_{2}\right\rangle$ since $\left(y_{2}, y_{1}\right) \in T^{*}$. Next note that $\left(x_{1}, x_{3}\right) \in S \circ T$ and thus $\left\langle x_{1}, y_{1}\right\rangle=\left\langle x_{3}, y_{3}\right\rangle$. Thus $\left\langle x_{2}, y_{2}\right\rangle=\left\langle x_{3}, y_{3}\right\rangle$ as was to be shown.

This proposition can be used to establish the closedness of some, but not very many, products.

Propositron 3.13. If $S$ is a closed relation between $X_{1}$ and $X_{2}$, $T$ a closed relation between $X_{2}$ and $X_{3}$, and either $R(T)=X_{3}$ and $D\left(S^{*}\right) \subseteq R\left(T^{*}\right)$ or $D(S)=X_{1}$ and $R\left(T^{*}\right) \subseteq D\left(S^{*}\right)$, then $T \circ S$ is a closed relation between $X_{1}$ and $X_{3}$. 
Proof. Certainly $S^{*} \circ T^{*} \subseteq(T \circ S)^{*}$. Hence $(T \circ S)^{* *} \subseteq\left(S^{*} \circ T^{*}\right)^{*}$. If we can show that $\left(S^{*} \circ T^{*}\right)^{*} \subseteq T^{* *} \circ S^{* *}=T \circ S$, we are finished, for then $(T \circ S)^{* *} \subseteq T \circ S$. But direct application of 3.12, substituting $S^{*}$ for $S$ and $T^{*}$ for $T$, asserts that $\left(S^{*} \circ T^{*}\right)^{*} \cong T^{* *} \circ S^{* *}$.

This proposition is true for any field, the proof given above being valid in such generality.

However, we now shift to the employment of properly topological methods to obtain a result for topological linear spaces which is stronger than 3.13 .

Proposition 3.14. Let $X_{i}$ and $Y_{i}$ be dual pairs over $C$. If $S$ is a closed relation between $X_{1}$ and $X_{2}, T \subseteq X_{2} \oplus X_{3}$ and either $R(T)$ is a closed subspace of $X_{3}$ and $D\left(S^{*}\right) \subseteq R\left(T^{*}\right)$ or $D\left(S^{*}\right)$ is a closed subspace of $Y_{2}$ and $R\left(T^{*}\right) \subseteq D\left(S^{*}\right)$ then $T \circ S$ is closed.

Proof. We shall only consider the first set of hypotheses. The other set is handled as in 3.12. Suppose $\left(d_{\gamma}, c_{\gamma}\right)$ is a net in $T \circ S$ and $\left(d_{\gamma}, c_{\gamma}\right) \rightarrow(d, c)$ in $\sigma(X, Y) \oplus \sigma(X, Y)$. We wish to show $(d, c) \in T \circ S$. Since $R(T)$ is closed, there exists $b \in X_{2}$ such that $(b, c) \in T$. If $(d, b) \in S$, we are finished. Since $S$ is closed, $(d, b) \in S$ if and only if for every $(x, y) \in S^{*},\langle d, y\rangle=\langle b, x\rangle$. Since $\left(d_{\gamma}, c_{\gamma}\right) \in T \circ S$ there exists $b_{\gamma} \in X_{2}$ such that $\left(d_{\gamma}, b_{\gamma}\right) \in S$ and $\left(b_{\gamma}, c_{\gamma}\right) \in T$. Since $D\left(S^{*}\right) \subseteq R\left(T^{*}\right)$, there exists $w$ such that $(w, x) \in T^{*}$. Thus $\left\langle d_{\gamma}, y\right\rangle=\left\langle b_{\gamma}, x\right\rangle$. But $\left\langle b_{\gamma}, x\right\rangle=\left\langle c_{\gamma}, w\right\rangle$. Thus since $\left\langle d_{\gamma}, y\right\rangle \rightarrow\langle d, y\rangle$ and $\left\langle c_{\gamma}, w\right\rangle \rightarrow\langle c, w\rangle$, $\langle d, y\rangle=\langle c, w\rangle$. However $\langle b, x\rangle=\langle c, w\rangle$ since $(b, c) \in T$ and $(w, x) \in T^{*}$. Hence $\langle d, y\rangle=\langle b, x\rangle$ as was to be shown.

Proposition 3.15. Let $X_{i}$ and $Y_{i}$ be dual pairs over $C$. If $S$ is a closed relation between $X_{1}$ and $X_{2}$ and $T \cong X_{2} \oplus X_{3}$ such that $R(T)$ is closed and $T^{-1}$ is singlevalued and continuous from

$$
\left(R(T),\left.\sigma(X, Y)\right|_{R(T)}\right) \rightarrow(X, \sigma(X, Y)),
$$

then $T \circ S$ is closed.

Proof. First note that the hypotheses on $T$ necessarily imply that $T$ is closed. Let $\left(d_{\gamma} c_{\gamma}\right)$ be a net in $T \circ S$ such that $\left(d_{\gamma}, c_{\gamma}\right) \rightarrow(d, c)$ in $\sigma(X, Y) \oplus \sigma(X, Y)$. Since $c_{\gamma} \rightarrow c$ in $\sigma(X, Y), T^{-1}\left(c_{\gamma}\right) \rightarrow T^{-1}(c)$. Since $T$ is closed, $\left(T^{-1}(c), c\right) \in T$ and since $S$ is closed, $\left(d, T^{-1}(c)\right) \in S$. Hence $(d, c) \in T \circ S$.

We now use 3.15 to prove a generalization of Taylor's theorem concerning polynomials in linear operators.

THeOREM 3.16. Let $X$ and $Y$ be a dual pair over $C$. If $T$ is a closed linear relation on $X$ such that for some $\lambda \in C, R(T-\lambda)$ is 
a closed subspace of $X$ and $(T-\lambda)^{-1}$ is singlevalued and continuous from $\left(R(T),\left.\sigma(X, Y)\right|_{R(T)}\right)$ to $(X, \sigma(X, Y))$, then for every polynomial $P, P(T)$ is a closed linear relation on $X$.

Proof. We will use induction and the fact that if $S$ is closed, $S+\alpha$ is closed for every $\alpha \in C$. Thus we may assume that for every polynomial $Q$ of degree $\leqq n, Q(T)$ is closed. Let $P(z)$ be an $(n+1)$ degree polynomial. Then there exists a polynomial $Q$ of degree $n$ such that for some $\alpha \in \boldsymbol{C}, P(z)-\alpha=(z-\lambda) \circ Q(z), z \in \boldsymbol{C}$. Hence by [1, 2. 3], $P(T)-\alpha=(T-\lambda) \circ Q(T)$. Now apply 3.15 with $T$ replaced by $T-\lambda$ and $S$ by $Q(T)$. Then $P(T)-\alpha$ is closed and hence $P(T)$ is closed.

4. Further investigation. In our doctoral dissertation [4], we have treated this theorem and related topics in greater detail.

\section{BIBLIOGRAPHY}

1. Richard Arens, Operation calculus of linear relations, Pacific J. Math. 11 (1961).

2. —, Duality in linear spaces, Duke Math. J. 14 (1947), 787-794.

3. S. Banach, Theorie des Operations Lineaires, Monografje Matematyczne, Warsaw, 1932.

4. M. J. Kascic, Jr., Polynomials in closed linear relations, Doctoral Dissertation, U. C. L. A. Mathematics Dept., (1967).

5. G. W. Mackey, On convex topological linear spaces, Trans. Amer. Math. Soc. 60 (1946).

6. H. H. Schaefer, Topological Vector Spaces, Macmillian Series in Advanced Mathematics and Theoretical Physics, 1966.

7. A. E. Taylor, Spectral analysis of closed distributive operators, Acat Math. 84 (1950).

Received February 12, 1967.

Dartmouth College 



\title{
PACIFIC JOURNAL OF MATHEMATICS
}

\author{
EDITORS
}

\section{H. ROYDEN}

Stanford University

Stanford, California

\section{J. P. JANS}

University of Washington Seattle, Washington 98105

\section{J. DugundJI}

Department of Mathematics

Rice University

Houston, Texas 77001

RICHARD ARENS

University of California

Los Angeles, California 90024

\section{ASSOCIATE EDITORS}

E. F. BECKENBACH
F. WOLF

K. YosidA

\section{SUPPORTING INSTITUTIONS}

\author{
UNIVERSITY OF BRITISH COLUMBIA \\ CALIFORNIA INSTITUTE OF TECHNOLOGY \\ UNIVERSITY OF CALIFORNIA \\ MONTANA STATE UNIVERSITY \\ UNIVERSITY OF NEVADA \\ NEW MEXICO STATE UNIVERSITY \\ OREGON STATE UNIVERSITY \\ UNIVERSITY OF OREGON \\ OSAKA UNIVERSITY \\ UNIVERSITY OF SOUTHERN CALIFORNIA
}

\author{
STANFORD UNIVERSITY \\ UNIVERSITY OF TOKYO \\ UNIVERSITY OF UTAH \\ WASHINGTON STATE UNIVERSITY \\ UNIVERSITY OF WASHINGTON \\ MERICAN MATHEMATICAL SOCIETY \\ CHEVRON RESEARCH CORPORATION \\ TRW SYSTEMS \\ NAVAL ORDNANCE TEST STATION
}

Mathematical papers intended for publication in the Pacific Journal of Mathematics should be in typed form or offset-reproduced, double spaced with large margins. Underline Greek letters in red, German in green, and script in blue. The first paragraph or two must be capable of being used separately as a synopsis of the entire paper. It should not contain references to the bibliography. Manuscripts may be sent to any one of the four editors. All other communications to the editors should be addressed to the managing editor, Richard Arens, University of California, Los Angeles, California 90024.

Each author of each article receives 50 reprints free of charge; additional copies may be obtained at cost in multiples of 50 .

The Pacific Journal of Mathematics is published monthly. Effective with Volume 16 the price per volume (3 numbers) is $\$ 8.00$; single issues, $\$ 3.00$. Special price for current issues to individual faculty members of supporting institutions and to individual members of the American Mathematical Society: $\$ 4.00$ per volume; single issues $\$ 1.50$. Back numbers are available.

Subscriptions, orders for back numbers, and changes of address should be sent to Pacific Journal of Mathematics, 103 Highland Boulevard, Berkeley 8, California.

Printed at Kokusai Bunken Insatsusha (International Academic Printing Co., Ltd.), 7-17, Fujimi 2-chome, Chiyoda-ku, Tokyo, Japan.

PUBLISHED BY PACIFIC JOURNAL OF MATHEMATICS, A NON-PROFIT CORPORATION

The Supporting Institutions listed above contribute to the cost of publication of this Journal, but they are not owners of publishers and have no responsibility for its content or policies. 


\section{Pacific Journal of Mathematics}

\section{Vol. 24, No. $2 \quad$ June, 1968}

John Suemper Alin and Spencer Ernest Dickson, Goldie's torsion theory and its derived functor . . . . . . . . . . . . . . . . . . . . . . . . . . . 195

Steve Armentrout, Lloyd Lesley Lininger and Donald Vern Meyer,

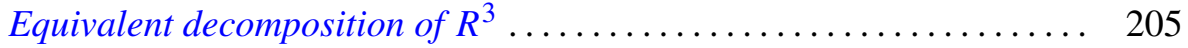

James Harvey Carruth, A note on partially ordered compacta ........... 229

Charles E. Clark and Carl Eberhart, A characterization of compact

connected planar lattices........................... 233

Allan Clark and Larry Smith, The rational homotopy of a wedge ......... 241

Donald Brooks Coleman, Semigroup algebras that are group algebras .... 247

John Eric Gilbert, Convolution operators on $L^{p}(G)$ and properties of

locally compact groups ............................. 257

Fletcher Gross, Groups admitting a fixed-point-free automorphism of order

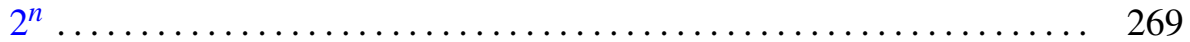

Jack Hardy and Howard E. Lacey, Extensions of regular Borel measures . . . 277

R. G. Huffstutler and Frederick Max Stein, The approximation solution of

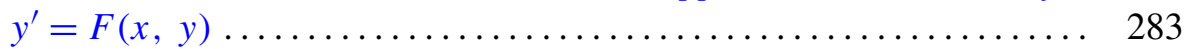

Michael Joseph Kascic, Jr., Polynomials in linear relations . . . . . . . . . . 291

Alan G. Konheim and Benjamin Weiss, A note on functions which

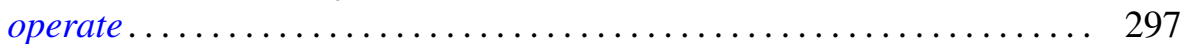

Warren Simms Loud, Self-adjoint multi-point boundary value problems ... 303 Kenneth Derwood Magill, Jr., Topological spaces determined by left ideals

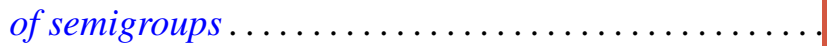

Morris Marden, On the derivative of canonical products . . .

J. L. Nelson, A stability theorem for a third order nonlinear differential

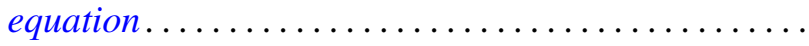

Raymond Moos Redheffer, Functions with real poles and zeros ...

Donald Zane Spicer, Group algebras of vector-valued functions ...

Myles Tierney, Some applications of a property of the functor $E f$ 